OPEN ACCESS

Edited by:

Alberto Battistelli,

Research Institute on Terrestrial

Ecosystems (CNR), Italy

Reviewed by:

Joaquín J. Salas,

Instituto de la Grasa (IG), Spain

Vinay Kumar,

Central University of Punjab, India

*Correspondence:

Lara Reale

lara.reale@unipg.it

${ }^{\text {t}}$ These authors have contributed equally to this work

Specialty section:

This article was submitted to Plant Metabolism and Chemodiversity,

a section of the journal

Frontiers in Plant Science

Received: 15 February 2019

Accepted: 14 November 2019

Published: 05 December 2019

Citation:

Cerri M, Reale L and Zadra C (2019)

Metabolite Storage in Theobroma

cacao L. Seed: Cyto-Histological and

Phytochemical Analyses.

Front. Plant Sci. 10:1599.

doi: 10.3389/fpls.2019.01599

\section{Metabolite Storage in Theobroma cacao L. Seed: Cyto-Histological and Phytochemical Analyses}

\author{
Martina Cerri ${ }^{1 \dagger}$, Lara Reale ${ }^{1 * t}$ and Claudia Zadra ${ }^{2}$ \\ ${ }^{1}$ Department of Agricultural, Food and Environmental Sciences, University of Perugia, Perugia, Italy, ${ }^{2}$ Department of \\ Pharmaceutical Sciences, University of Perugia, Perugia, Italy
}

Cocoa (Theobroma cacao L.), an economically important tropical-fruit crop as source of chocolate, has recently gained a considerable attention; its seeds contain a large amount of different bioactive compounds that have attracted interest because may be beneficial to humans by improving cardiovascular health, by cancer chemo-preventive effects and also through neuroprotective activities. The morphological and anatomical characteristics of cocoa seeds are closely related to the aroma and to the nutritional properties. This study aimed to provide more information about the storage of some metabolites in the various components of cocoa seed by microscopical and phytochemical analyses. Polyphenols, sterols, tocopherols and fatty acids were detected in different portions of the seeds (teguments, cotyledons, embryo axis and pulp). Quali and quantitative differences were observed and a characteristic polyphenol pattern was detected in the different portions of the seed; cytological analysis demonstrated the presence of these compounds in big vacuolated polyphenolic cells. Among the analyzed fatty acids, the stearic and oleic acids were the most abundant in all the seed components (teguments, cotyledons and embryo axis). Fatty acids, usually found in the form of esters, thioesters and amides, represent one of the storage substances of cocoa seed probably localized in lipid globules, which in our observations occupied almost the entire volume of small isodiametric cells of cotyledon mesophyll. In the cocoa seeds we observed also a different distribution of sterols: $\beta$ sitosterol and $\Delta 5$-avenasterol were the most abundant, above all in the embryo axis; stigmasterol and campesterol were less present in embryo axis and more abundant in teguments; campestanol level was again higher in teguments but lower in cotyledons. The specific localization of different kind of sterols was probably related to a peculiar function. Our experiments demonstrated that all seed components contribute to the metabolites storage, but with interesting differences in the localization and amount of each metabolite.

Keywords: antioxidant, cotyledons, histology, lipids, polyphenols, teguments 


\section{INTRODUCTION}

Cocoa (Theobroma cacao L.) belongs to the family Sterculiaceae. It is an economically important tropical-fruit crop, mainly known as the source of chocolate and was introduced to Europe during the 16th century.

The fruit of cocoa tree is a pod, or cherelle, which shape and colour can differ among morphogenetic groups. Each pod holds 20 to 60 seeds, or beans, embedded in a white pulp, and is constituted by a thick epicarp, of variable hardness and with a pigmented epidermis, a thin and hard mesocarp, more or less woody, and finally the endocarp (Bertazzo et al., 2013). The endocarp is composed by big tubular cells with large intercellular spaces which, in the ripe seeds, collapse and form the so-called pulp. Pulp is rich in water and nutrients, contains $10-15 \%$ of sugar, is characterized by a low $\mathrm{pH}(3.6-4.0)$ and plays an important role during the seed fermentation, contributing to the flavour development (Hui et al., 2006).

The potential health implications of biologically active substances present in cocoa seeds are well documented. They are rich in natural antioxidants, such as polyphenols and tocopherols. Thanks to this antioxidant property, many of these compounds, especially flavonoids, exhibit also a wide range of pharmacologic effects, including antibacterial, antiviral, anti-inflammatory, antiallergic, antithrombotic and vasodilatory actions (Cook and Samman, 1996; Batista et al., 2016). The high levels of flavanols are responsible for the bitterness of cocoa that represent a fundamental aspect of the organoleptic and palatability characteristics of chocolate, and contribute to cocoa health benefits (Jalil and Ismail, 2008).

Epicatechins (that are classified as flavan-3-ols, based on their structure) are the most abundant cocoa phenolic components; they mainly include monomeric (-) epicatechin and $(+)$ catechin (as well as oligomeric and polymeric proanthocyanidin flavanols), gallocatechin and epigallocatechin (Ortega et al., 2008).

Epicatechin represents approximately $35 \%$ of polyphenol content of unfermented Forastero cocoa beans (Othman et al., 2010). The antioxidant properties are also related to the presence of tocopherols and tocotrienols, which reduce oxidative stress and delay the progress of a variety of degenerative disorders, such as cardiovascular diseases and cancer. In addition, they have been shown to regulate cellular signalling, cell proliferation and gene expression (Sen et al., 2007). The total tocopherol content in cocoa beans is reported to be in a range of $100-300 \mathrm{mg} / \mathrm{Kg}$ fat (Carpenter et al., 1994; Shukla et al., 2005), values that are similar to those generally observed for wheat germ oil (Beliz and Grosch, 1999). The predominant isomer in cocoa bean is the gammatocopherol and a different distribution of the four isomers in seed parts of Theobroma subincanum were described by Bruni et al., 2002.

Precursors of tocopherols and polyphenols are produced from the plant primary biosynthetic shikimate and acetate pathways. The main products of these pathways are the aromatic amino acids phenylalanine (Phe), tyrosine (Tyr) and tryptophan (Trp) and acetyl-coenzyme A (CoA), respectively.
They represent the starting molecules for the biosynthesis of a wide range of secondary metabolites (Tzin et al., 2012).

Other interesting classes of cocoa bioactive constituents are represented by phytosterols (collective terms comprising saturated sterols, also known as stanols) and fatty acids. Phytosterols are typical plant lipids which have a structural similarity with cholesterol and inhibit its intestinal absorption, contributing to a lower total plasma cholesterol and low-density lipoproteins levels. In cocoa seeds, the content of plant sterols is $2-3 \mathrm{mg} / \mathrm{g}$ fat, with an abundance of $\beta$-sitosterol and stigmasterol (Staphylakis and Gegiou, 1985) . Fatty acids are organized as triacylglycerol (TAG), the majority of these TAG's being 2-oleyl glycerides $(\mathrm{O})$ of palmitic $(\mathrm{P})$ and stearic $(\mathrm{S})$ acids (POP, POS, SOS) (Simoneau et al., 1999; Segall et al., 2005). This TAG structure directly affects the way chocolate behaves in the manufacturing process and the characteristics of the final product (texture, viscosity, melting behaviour, flavour and taste) (Afoakwa, 2010). The fatty acids content depends on the variety and region of cultivation of cocoa beans (Bruni et al., 2002; Torres-Moreno et al., 2015).

The biosynthesis of fatty acids requires as precursor the acetyl-CoA, that also represents the starting point of the mevalonate pathway from which arise the secondary metabolites, sterols/phythosterols.

The presence of above-mentioned compounds (as polyphenols, phytosterol and fatty acids) is not the only trait influencing the nutritional characteristics and aroma of cocoa beans, their morphological and anatomical traits, as the permeability of the seed coat, are also very important aspects. Andersson et al. (2006) suggested that water and solutes flow through seed coat during the fermentation process was strongly related to the flavour quality. The acetic acid produced during the fermentation moves thought the seed coat to contribute to formation of flavour precursors in the cotyledons. The uptake of acetic acid is also influenced by the fruit pulp and the inner pulp epidermis. The cyto-histological characteristics of cotyledons parenchyma are also important; the size of cells can influence the diffusion of acetic acid into the seed, because cells with higher volume can provide larger spaces for chemical reactions (Biehl, 1973; Biehl et al., 1977). After a comparison between different clones and varieties of cocoa, Elwers et al. (2010) suggested that 'the larger polyphenol and storage cells of Criollo seeds may contribute to the unique quality of this fine flavour cocoa'. Considering the important role of histo-anatomical traits, microscopy studies can be very useful to understand how metabolic processes are compartmentalized in plant tissues (Walker et al., 2001). The aim of this study is to better investigate the cyto-histological characteristics of cocoa seeds related to their composition in secondary metabolites, such as polyphenol and tocopherols. To our knowledge, there are in literature many data about the histological characterization of cocoa seeds (Martini et al., 2008; Elwers et al., 2010), as well as biochemical studies about its phenolics content and antioxidant capacity (Aprotosoaie et al., 2016; Endraiyani et al., 2016; Wang et al., 2016), but a specific localization of the phytochemicals in the different structures of seed and fruit has not been carried out 
yet. Metabolite localization was focused until now in the cotyledon structure, but, as previous described, also other structure of seed and fruit are important for the flavour development and nutritional characteristics. Knowledge about chemical composition and metabolite storage in the fruit wall of seed tegument can be also useful for the possible use of residual biomass originated during cocoa processing and for the presence of anticancer agents in these non-edible portions of cocoa (Zainal et al., 2014). Our research supplies a more complete picture of metabolites localization in all portions of cocoa seed and fruit.

\section{MATERIALS AND METHODS}

\section{Plant Material}

Samples were collected from fresh fruits of cocoa, harvested at maturity, coming from the municipality of Tucupita, Delta Amacuro state, Venezuela, and kindly donated to our University. The cocoa plantations of the Delta are established essentially in the tropical humid forest, in fertile alluvial soils with problems of poor drainage and in some units of tropical dry forest, with humid edaphic associations (Reyes and Capriles De Reyes, 2000; Gómez and Azócar 2002; Ministerio del Poder Popular para la Ciencia y Tecnología (MPPCT), 2006), in this area in general the soils have drainage problems and are flooded at certain times of the year (Corporación Venezolana de Guayana (CVG), 2006).

Seeds were separated from the rest of the fruit and their different components were progressively isolated. When gently removed from the fruit, seeds conserve mucilage, a portion of the modified endocarp; seeds with mucilage represent the first sample of this study (SM). In other seeds, mucilage was removed and seeds without mucilage were considered (S); the last samples were represented by the only teguments $(\mathrm{T})$, embryo axis (EA) and cotyledons (C) isolated from seeds. All the samples were pulverized with liquid nitrogen and silicon dioxide in a mortar.

\section{Cyto-Histological Observations}

Cocoa seeds were collected from a fresh fruit of cocoa; portions of fruit pericarp, seed T, C and embryo were fixed in 3\% (w/v) glutaraldehyde in $0.075 \mathrm{M}$ cacodylate buffer, $\mathrm{pH} 7.2$, for $24 \mathrm{~h}$. The samples were then washed three times for $7 \mathrm{~min}$ in $0.075 \mathrm{M}$ cacodylate buffer, $\mathrm{pH} 7.2$, post-fixed in $1 \%(\mathrm{w} / \mathrm{v}) \mathrm{OsO}_{4}$ in the same buffer for $1 \mathrm{~h}$, dehydrated in increasing concentrations of ethanol and finally embedded in epoxy resin (Epon, 2dodecenylsuccinic anhydride and methylnadic anhydride mixture) (Reale et al., 2017, with modifications). Semi-thin sections $(1-2 \mu \mathrm{m})$, obtained with an ultramicrotome (OmU2, Reichert, Heidelberg) after staining were observed under a light microscope (BX53; Olympus, Tokyo, Japan).

\section{Periodic Acid Schiff's Reaction}

Semi-thin sections were treated with $0.5 \%$ periodic acid for 30 min at $40^{\circ} \mathrm{C}$, washed with tap and demineralized water and covered with Schiff's reagent for 15 min (O'Brien and McCully, 1981). Sections were then washed rapidly with tap water, two times for 3 min with $\mathrm{SO}_{2}$ water and two times for $10 \mathrm{~min}$ with demineralized water. Sections were also counter-stained with $1 \%$ $(\mathrm{w} / \mathrm{v})$ amido black in $7 \%$ acetic acid for protein. The presence of proteins was indicated by a blue colour, whilst starch grains appeared magenta.

\section{Toluidine Blue Staining}

Semi-thin sections were covered with $0.5 \%(\mathrm{w} / \mathrm{v})$ toluidine blue in $2 \% \mathrm{NaHCO}_{3}$ buffer. Toluidine blue has a high affinity for acidic tissue components and stains nucleic acids blue and polysaccharides purple (Feder and O’Brien, 1968).

\section{Toluidine Blue O Staining}

Semi-thin sections were stained with $0.5 \%(\mathrm{w} / \mathrm{v})$ toluidine blue $\mathrm{O}$ in $0.1 \mathrm{M}$ phosphate buffer, $\mathrm{pH}$ 7.2. The metachromatic stain develops a green-blue colour when associated with polyphenolic compounds, whilst turns pink with pectic substances and purple with nucleic acids and protein (Feder and O'Brien, 1968).

\section{Vanillin Staining}

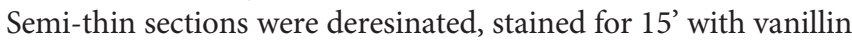
$(10 \% \mathrm{w} / \mathrm{v})$ in ethanol mixed with $12 \mathrm{M} \mathrm{HCl}(2: 1, \mathrm{v} / \mathrm{v})$ (Earp et al., 2004), and mounted in glycerin. Vanillin turns up red upon binding to flavan-3,4-diols and flavan-4-ols (catechins), which are present either as monomers or as terminal subunits of proanthocyanidins.

\section{Chemicals}

All the chemicals were of analytical grade and, unless otherwise specified, were purchased from Merck (Darmstadt, Germany).

\section{Chemical Analyses}

For chemical analysis the considered samples (SM, S, T, C, EA) were collected from different seeds, pooled and analyzed in triplicates.

\section{Analysis of Total Polyphenolic Compounds Content}

The total phenolic compounds were extracted from defatted cocoa samples (SM, S, T, C, EA) (through exhaustive extraction with $n$-hexane) with a mixture of acetone and water 80:20 (v/v) in an ultrasonic bath for $15 \mathrm{~min}$. After centrifugation the supernatant was filtered, and this procedure was repeated twice. The supernatants were combined, the acetone was evaporated under vacuum and the residue was analyzed for the total phenolic contents using Folin-Ciocalteu's procedure (Singleton and Rossi, 1965). The total phenolic contents were calculated as a gallic acid equivalent (GAE) from a calibration curve of GA standard solutions and expressed as mg of GAE/g of sample.

\section{Antioxidant Activity of Cocoa Polyphenol Extracts}

The extracts were analyzed for their total antioxidant activity using the 2,2'-azino-bis(3-ethylbenzothiazoline-6-sulfonic acid (ABTS) method (Miliauskas et al., 2004). The $\mathrm{ABTS}^{+}$radical was generated by oxidation of ABTS with potassium persulfate, then 
$1 \mathrm{ml}$ of extract was added to the radical solution and the absorbance measured at $734 \mathrm{~nm}$. Standard Trolox solutions were evaluated against the radical in order to obtain the calibration curve. The results of the antioxidant activity of cocoa extracts are expressed in terms of Trolox equivalent antioxidant capacity (TEAC) as mMol Trolox/g of sample.

\section{High-Performance Liquid Chromatography-Analysis of the Extracts for Polyphenols and Tocopherols Identification}

The samples of the previous aqueous extract derived from T, C and seed (with and without mucilage, SM and S) were analyzed by high-performance liquid chromatography (HPLC) for the identification of the polyphenolic compounds. Analyses were performed on a Perkin-Elmer PE 200 system (autosampler, binary pump and UV-Vis detector) equipped with an Inertsil 5 ODS-3 (250 mm x $4.6 \mathrm{~mm}$ i.d. x $5 \mu \mathrm{m}$, Varian) at a flow rate of $1.5 \mathrm{ml} \mathrm{min}{ }^{-1}$; the injection volume was $20 \mu \mathrm{l}$, and detection was made in a spectrum from 280 to $530 \mathrm{~nm}$ for the different classes of compounds. The mobile phase consisted of (A) $1 \%$ acetic acid in water and (B) acetonitrile (80): water $1 \%$ acetic acid (20). The program was as follows: isocratic with solvent (B) for $20 \mathrm{~min}$, linear gradient to $100 \%$ (A) for $15 \mathrm{~min}, 15 \mathrm{~min}$ linear gradient to solvent (B). The compounds were identified by comparing the retention times and areas with those of appropriate standards used for the calibration curve.

For the HPLC-analysis of the tocopherols in the T and C, these vegetable parts were suspended in $5 \mathrm{ml}$ of methanol and sonicated (Branson 2800, Danbury, USA) for $20 \mathrm{~min}$, the mixture was then filtered, rinsed with the solvent and evaporated under vacuum. The methanolic fractions were processed by a second extraction with $5 \mathrm{ml}$ of $\mathrm{n}$-hexane and dried under vacuum. HPLC analyses were performed on a Perkin-Elmer PE 200 system (autosampler, binary pump and UV-Vis detector) equipped with a LiChrosorb Si60 (250 mm x 4 mm i.d. x $5 \mu \mathrm{m}$ column Phenomenex), the mobile phase was $0.05 \%$ isopropanol/hexane at a flow rate of $1 \mathrm{ml} / \mathrm{min}$, the wavelength was $295 \mathrm{~nm}$ and the injection volume $20 \mu \mathrm{l}$. Tocopherols peaks from samples were identified by comparing the retention times with those of authentic reference compounds (tocopherols mix pure standards, Sigma-Aldrich). The compounds were quantified by an external standard method, using a calibration curve. For each extract, quali-quantitative analyses were performed in triplicates.

The lack of a sufficient amount of sample has not allowed to perform these analyses in the embryo.

\section{Analysis of Fatty Acids}

In the samples $\mathrm{T}, \mathrm{C}$, EA the lipid fraction (from hexane extraction) was subsequently derivatized into fatty acid methyl esters (FAMEs) by mild alkaline methanolysis. FAMEs were extracted twice with $2 \mathrm{ml}$ aliquots of hexane:chloroform $(4: 1 \mathrm{v} / \mathrm{v})$ and the pooled aliquots were dried under $\mathrm{N}_{2}$ at room temperature and redissolved in hexane-containing methyl nonadecanoate (C19:0) as internal standard. FAMEs were analyzed by gas chromatography-flame ionization detector
(GC-FID) detector (Trace 2000, Thermo-Fisher) equipped with a $100 \%$ dimethyl-polysiloxane non-polar column (50 m length, $0.25 \mathrm{~mm}$ i.d. and $0.25 \mathrm{~mm}$ film thickness, Agilent $\mathrm{J} \& \mathrm{~W}$ ) and a split/splitless injector (1/10 ratio). The temperatures of the injector and detector were 220 and $250^{\circ} \mathrm{C}$, respectively. The oven was temperature-programmed from $60^{\circ} \mathrm{C}(5 \mathrm{~min})$ to $300^{\circ} \mathrm{C}$ ( $5 \mathrm{~min}$ ) at a rate of $25^{\circ} \mathrm{C} / \mathrm{min}$. The injection volume was $1 \mu \mathrm{l}$. Preliminary peak identification was carried out by comparison of retention times with known standards. Relative amounts of given fatty acids were calculated from their respective chromatographic peak areas and the relative percentage of each fatty acid was related to the total peak areas of both saturated and unsaturated fatty acids.

\section{Analysis of Phytosterols}

In the samples T, C, EA the hexane extract was saponified with 2 $\mathrm{M}$ methanolic potassium hydroxide for $1 \mathrm{~h}$ at $70^{\circ} \mathrm{C}$ in ultrasonic bath, then was added $2 \mathrm{ml} \mathrm{H}_{2} \mathrm{O}$ and $3 \mathrm{ml}$ hexane, vortexed and the two phases separated. Sterols were extracted from aqueous phase for three times. The organic phases were collected, added with anhydrous sodium sulphate and evaporated to dryness. Samples dissolved in $50 \mu \mathrm{l}$ of $\mathrm{CHCl}_{3}$ were derivatized as corresponding trimethylsilyl ether by adding $150 \mu \mathrm{l}$ of bis (trimethylsilyl)trifluoroacetamide and heated for $1 \mathrm{~h}$ at $60^{\circ} \mathrm{C}$. The samples were evaporated to dryness under a gentle stream of $\mathrm{N}_{2}$ and then redissolved in $1 \mathrm{ml}$ of $\mathrm{CHCl}_{3}$. GC-FID (Trace 2000, Thermo-Fisher) analyses were performed with a fused-silica capillary column $(30 \mathrm{~m}$ length $\times 0.25 \mathrm{~mm}$ i.d. $\times 0.25 \mu \mathrm{m}$ film thickness, Agilent J\&W). The oven was temperatureprogrammed from $180^{\circ} \mathrm{C}(3 \mathrm{~min})$ to $280^{\circ} \mathrm{C}(5 \mathrm{~min})$ at a rate of $10^{\circ} \mathrm{C} / \mathrm{min}$ and to $300^{\circ} \mathrm{C}(10 \mathrm{~min})$ at a rate of $10^{\circ} \mathrm{C} / \mathrm{min}$. The temperatures of the injector and detector were 250 and $280^{\circ} \mathrm{C}$, respectively. The sample volume was $1 \mu \mathrm{l}$ with a split injection $(1 / 20)$. Preliminary peak identification was carried out by comparison of retention times with known standards and external calibration was carried out.

\section{Statistical Analysis}

Data were checked for normality and homoscedasticity; afterwards, they were analyzed by one-way analysis of variance (ANOVA) or T-Student test. Mean separations were performed using the least significant difference (LSD) test at $\mathrm{P}=0.05$. Analyses were conducted in R environment (R Core Team, 2017).

\section{RESULTS}

\section{Cyto-Histological Observations}

Cocoa pod was characterized by a thin epicarp, a fleshy mesocarp and the endocarp. In the mesocarp, large cells rich in water were alternated with smaller polyphenolic cells (Figures 1A-D), in which vesicles of polyphenolic substances were localized in the periphery of cells; numerous gaps were also observed. In the endocarp, big tubular cells with large intercellular spaces were detected; the periodic acid-Schiff (PAS) and toluidine blue $\mathrm{O}$ staining showed the presence of pectins (coloured in magenta) 

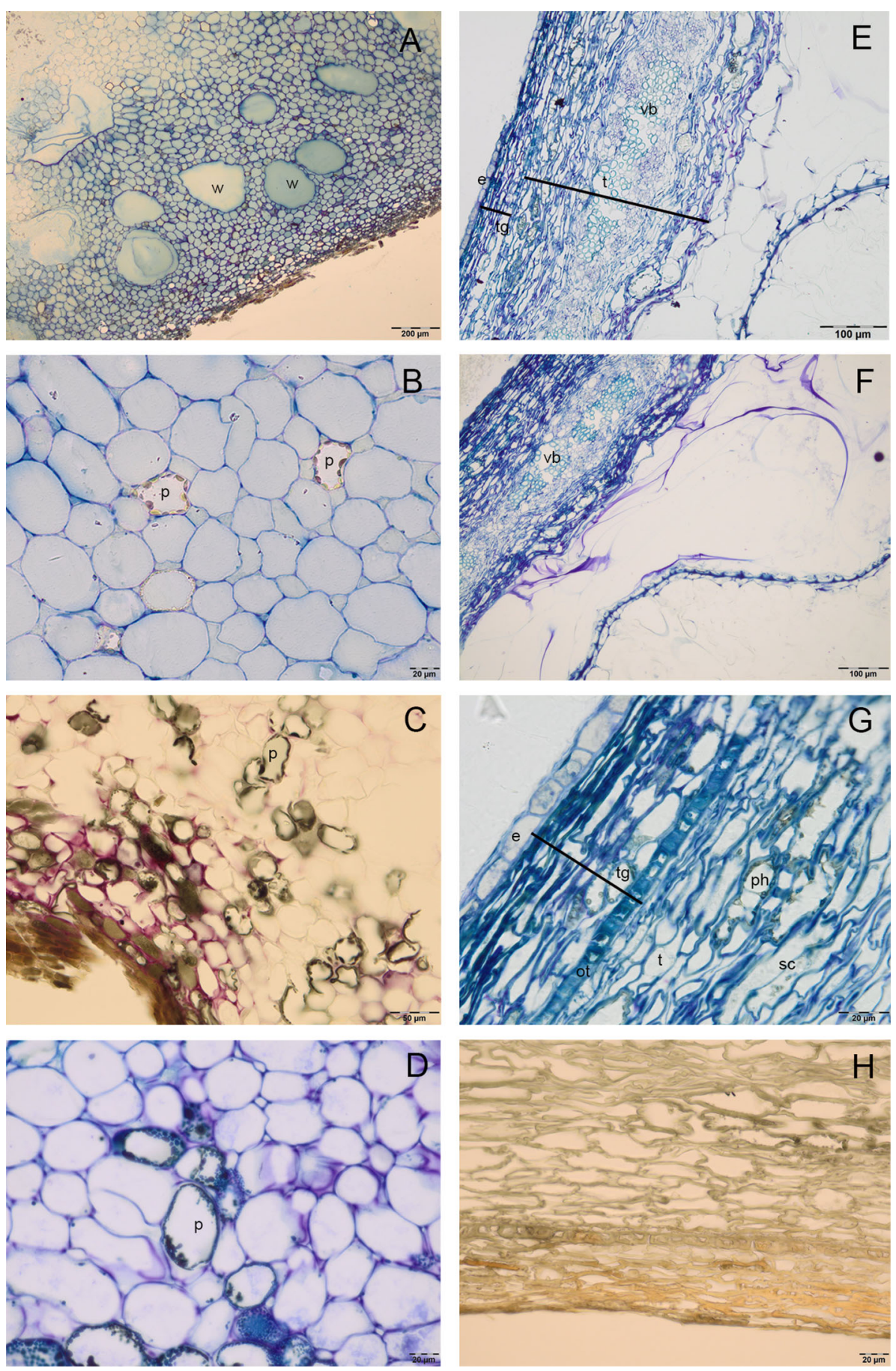

FIGURE 1 | Semithin sections of cocoa fruit and seed. (A-D) Fleshy mesocarp of pod, stained with toluidine blue (A, B), vanillin (C) and toluidine blue O (D), in which large cells rich in water (w) and polyphenolic cells (p) are detected. (E-F) Big tubular cells of endocarp with cell walls rich in pectins, which appeared coloured in magenta after toluidine blue $\mathrm{O}(\mathbf{E})$ and PAS staining (F); seed tegument constituted by testa (t) and tegmen (tg, in the mesophyll of testa it is possible to distinguish numerous vascular bundles (vb). (G) Single layered endosperm (e) adheres to seed tegument, in the tegmen we can identify an outer epidermis (ot), composed by sclerified cells (sc) and more layers of crashed cells; polyphenolic substances (ph) are evident in the region of sclerified cells of testa. (H) Tegument stained with vanillin: no epicatechin or catechin presence was detected.

in the wall of these cells (Figures 1E, F). Endocarp cells formed, in ripe seeds, a mucilaginous pulp that adhered tightly to seed coat (Figures 1E, F). In the seed coat, testa was constituted by an exotesta, a single layer of elongated cells, a mesophyll, in which there were numerous vascular bundles, and lignified stellate cells (Figures 1F, G). In tegmen it was possible to distinguish the outer 
epidermis, composed by one layer of sclereid cells with a thickened wall, many layers of crushed cells and the inner single-layered epidermis. In $\mathrm{T}$ polyphenolic substances were evident above all in the region of lignified stellate cells of testa (Figure 1G). The secondary endosperm was constituted by a single layer of cells, with lightly thickened outer walls (Figure 1G); it adhered to the seed coat and to numerous folding of the cotyledon tissue. In the T (Figure 1H) or mesocarp (Figure 1C), the vanillin staining did not reveal the presence of catechin, epicatechin or proanthocyanidins.

The $\mathrm{C}$ were foliaceous and densely folded near the EA, then became fleshy and darker for the anthocyanins synthesis (Figures 2A, B); they were formed by a two single-layered epidermis and a mesophyll rich in reserve substances. In the cotyledon mesophyll it was possible to distinguish two kind of cells: big vacuolated cells, containing vesicles of different size, which can be identified as polyphenolic cells; smaller isodiametric cells, rich in cytoplasm (Figures 2C-F). Fresh sections showed the presence of anthocyanins in some of the big vacuolated cells, which appeared in some cases also rich in phenolic compounds after staining with toluidine blue $\mathrm{O}$ (Figure 2E). Vanilline staining demonstrated the localization in some of these cells of catechin and epicatechin (Figures 2C, F). In the small isodiametric cells, PAS staining demonstrated the presence of starch grains (magenta colour) (Figure 2D); in the same cells lipid bodies were also detected (Figure 2D).

In the embryo axis, constituted by isodiametric tightly stuck cells arranged in parallel lines, the toluidine blue staining sharpened the presence of 5/6 superficial layers of polyphenolic
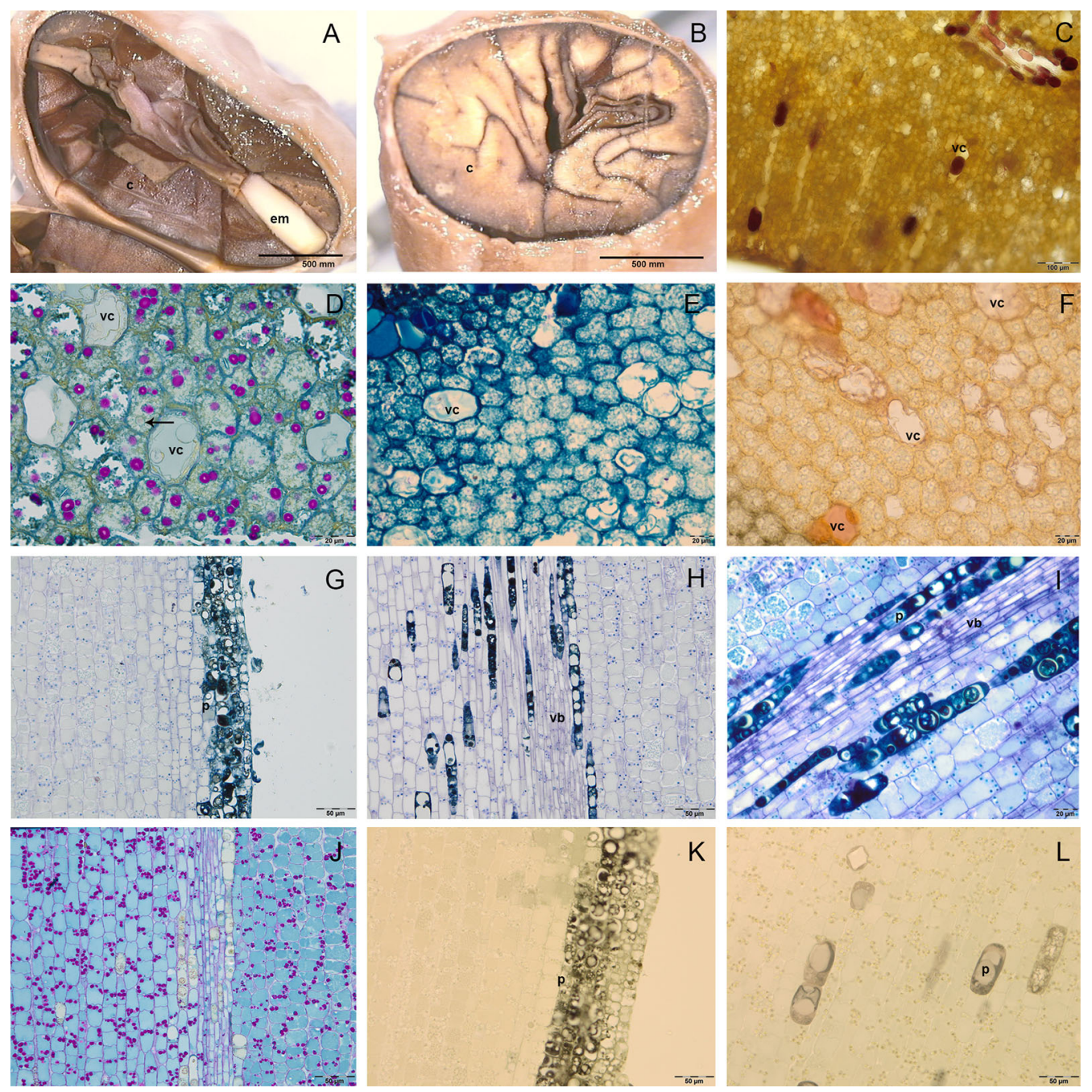

FIGURE 2 | Semithin (D-L) and fresh (A-C) sections of cocoa fruit and seed. (A-B) Fresh section of cocoa seeds: embryo axis (em) and brown cotyledons (c) are evident; cotyledons are foliaceous near the embryo axis and then become fleshy and densely folded. (C) Fresh section of cotyledons with big vacuolated cells (vc) rich in anthocyanins. (D-F) Semi-thin sections of cotyledons stained with periodic acid-Schiff (PAS) (D), toluidine blue O (E), vanillin (F); in cotyledons mesophyll, big vacuolated cells (vc) appeared rich in epicatechin after vanillin staining (F), whilst small cells showed lipid drops (black arrows) and starch grains coloured in magenta after PAS staining. (G-L) Semi-thin sections of embryo axis, stained with toluidine blue (G, H), toluidine blue $\mathrm{O}(\mathbf{I})$, PAS (J), vanillin (K, L); polyphenolic cells (p) are evident in the superficial layers (G) and near the vascular bundles (vb) (H, I); the presence of starch grains (magenta colour) is evident (J); no catechin or epicatechin were detected $\mathbf{( K}, \mathbf{L})$. 
cells (Figure 2G), which were observed also near to vascular bundles located in the center of embryo axis (Figure $\mathbf{2 H}$ ). The polyphenolic content of these cells was confirmed also by staining with toluidine blue $\mathrm{O}$ (Figure 2I). In the same portions, PAS staining demonstrated also the presence of starch grains (Figure 2J). No catechin or epicatechin were detected through vanillin staining (Figures $2 \mathbf{K}, \mathbf{L}$ ).

\section{Phytochemical Analysis}

The distribution of polyphenols, tocopherols, fatty acids and sterols were also evaluated in the different seed parts with the aim to better characterize them and to confirm the histological data. Particularly relevant was the significantly highest abundance of total polyphenols in the $\mathrm{T}$, data confirmed by the results of the antioxidant activity (TEAC value) of the different cocoa extracts (Figure 3). The content of polyphenols and TEAC were significantly lower in $S$ (seed without mucilage) than in the SM (seed with mucilage) sample, showing that the mucilage contributes greatly to the content of these phytochemicals and to the antioxidant activity. The individual phenolic content was investigated in the samples T, C, S, SM. As shown in Table 1, whole seed samples, S and $\mathrm{SM}$, were qualitatively richer in phenolic compounds than the other isolated seed components. Moreover, in S and SM samples there was a significantly higher abundance of chlorogenic acid, hydroxycinnamic, vanillic and ferulic acid.

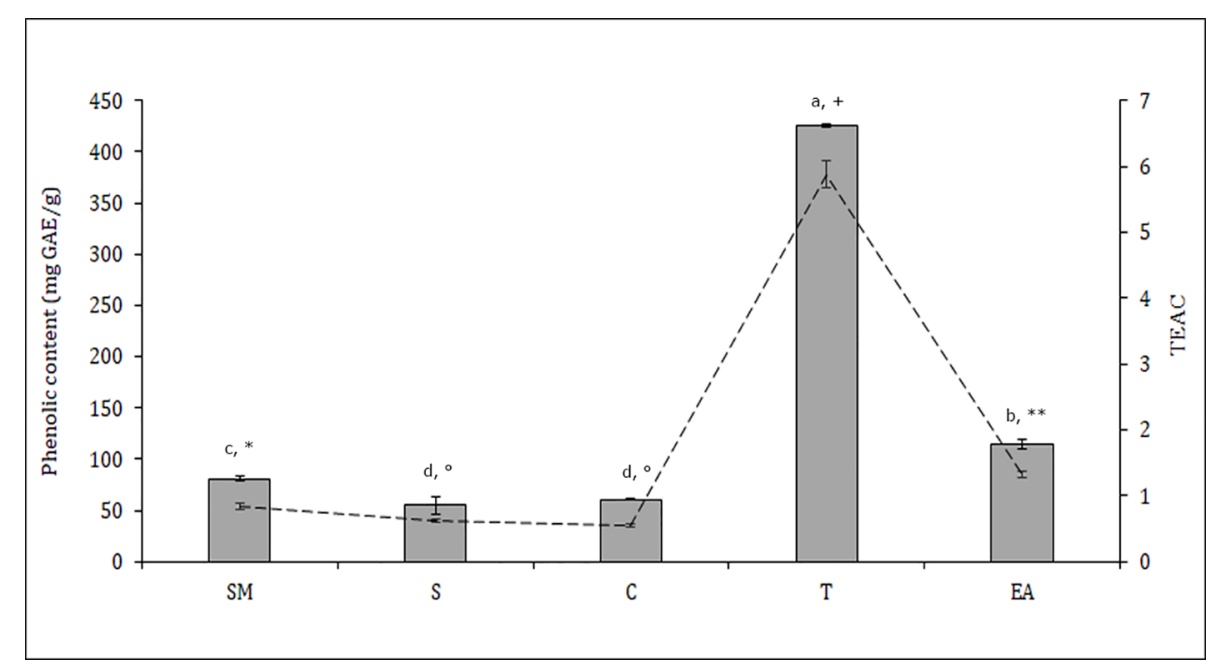

FIGURE 3 | Total phenolic content (bars) and antioxidant activity Trolox equivalent antioxidant capacity (TEAC) (dashed line) in different Theobroma cacao seed samples; T, tegument; C, cotyledons; SM, whole seed; S, seed without mucilage; EA, embryo axis (see Materials and Methods). The values represent means \pm SD of three replicates. Different letters and symbols indicate statistically significant differences according to LSD test $(p \leq 0.05)$ for phenolic content and TEAC, respectively.

TABLE 1 | Phenolic compounds content in different Theobroma cacao seed components.

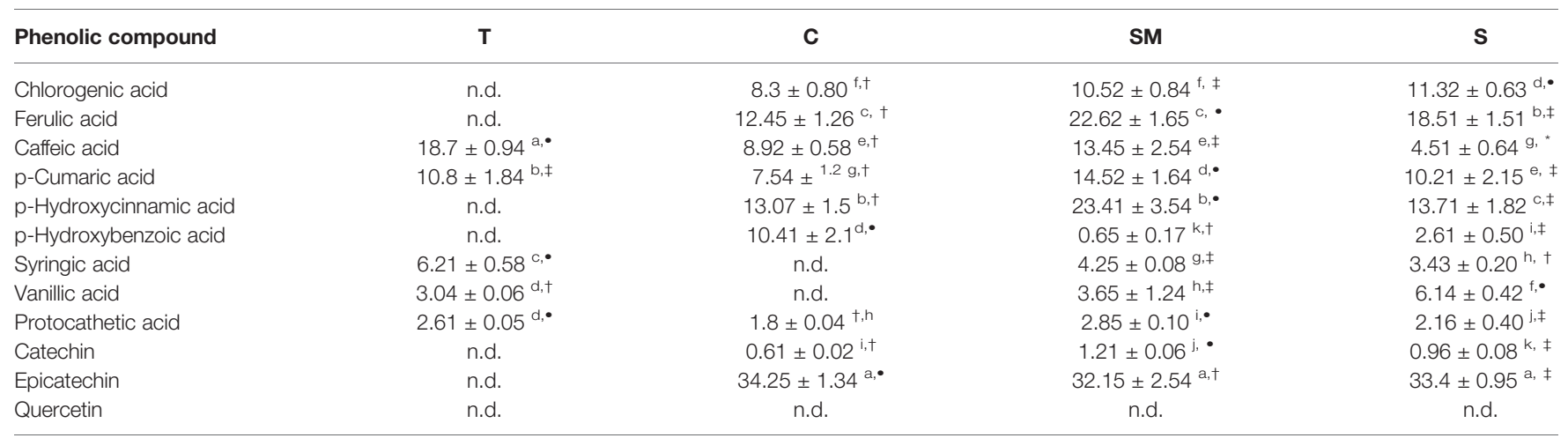

$T$, tegument; C, cotyledons; SM, whole seed; S, seed without mucilage (see Materials and Methods). Results are expressed as mean milligram/gram sample \pm SD of three replicates. In each column, different letters indicate statistically significant differences according to least significant difference (LSD) test ( $p \leq 0.05)$; in each row, different symbols indicate statistically significant differences according to LSD test ( $p \leq 0.05)$. n.d., not detected. 
Caffeic and syringic acids were, instead, more abundant in the $\mathrm{T}$; caffeic acid together with p-cumaric and protocathetic acid were the only components present in all the analyzed samples. Catechin and epicatechin were not detected in the T but present in C, SM and S; particularly epicatechin was the most abundant compound isolated in S, SM and C sample (e.g., 34\% of the total phenols in C). Quercitin was not detected in any analyzed samples. The total tocopherols content was analyzed in the single components of seed, $\mathrm{T}$ and $\mathrm{C}$ samples; it was higher in $\mathrm{C}$ with respect to the $\mathrm{T}(1.84 \pm 0.07 v s .1 .43 \pm 0.04 \mathrm{mg} / \mathrm{g})$. The distribution of the single isomers can be different in these two parts of the seed; this is true for $\alpha, \beta$ and $\delta$-tocopherol but not for $\gamma$-tocopherol (Figure 4); indeed $\beta$ and $\delta$-tocopherol were higher in $\mathrm{C}$ whilst the $\mathrm{T}$ was richer in $\alpha$-tocopherol.

The phytosterols characterization of seed parts showed a qualitative homogenous distribution with a quantitative predominance of $\beta$-sitosterol in all the three seed components (T, C, EA) with respect to the others (Table 2). In our samples the concentrations of the single compounds were significantly higher in $\mathrm{T}$ in comparison to the other seed parts, except for $\beta$ sitosterol and $\Delta 5$-avenasterol that were detected in significantly larger amount in the embryo-axis (Table 2).
The fatty acids profiles showed a homogeneous content of saturated (SFA; palmitic, stearic and arachidic) and unsaturated (UFA, palmitoleic, oleic, linoleic and linolenic) fatty acids among the different seed components (Table 3). The oleic acid C18:1 was, in all samples, the most representative unsaturated fatty acid, whilst stearic was the most abundant SFA. The SFA content were always higher than UFA; the ratio $\mathrm{S} / \mathrm{U}$ (saturated $v s$. unsaturated) was in a range of 1.46-1.67.

\section{DISCUSSION}

Recently, the interest about cocoa has increased due to the demonstrated benefit activity of cocoa extracts; they showed cardioprotective effects but also seemed to reduce inflammations and cholesterol levels (Engler and Engler, 2004; Cooper et al., 2008; Tokede et al., 2011). The composition of these extracts has been investigated during the different phases of seed development, but few information is yet available about their distribution in different fruit and seed components.

Our data outlined that antioxidant molecules, as tocopherols and polyphenols, were differentially distributed in cocoa fruit

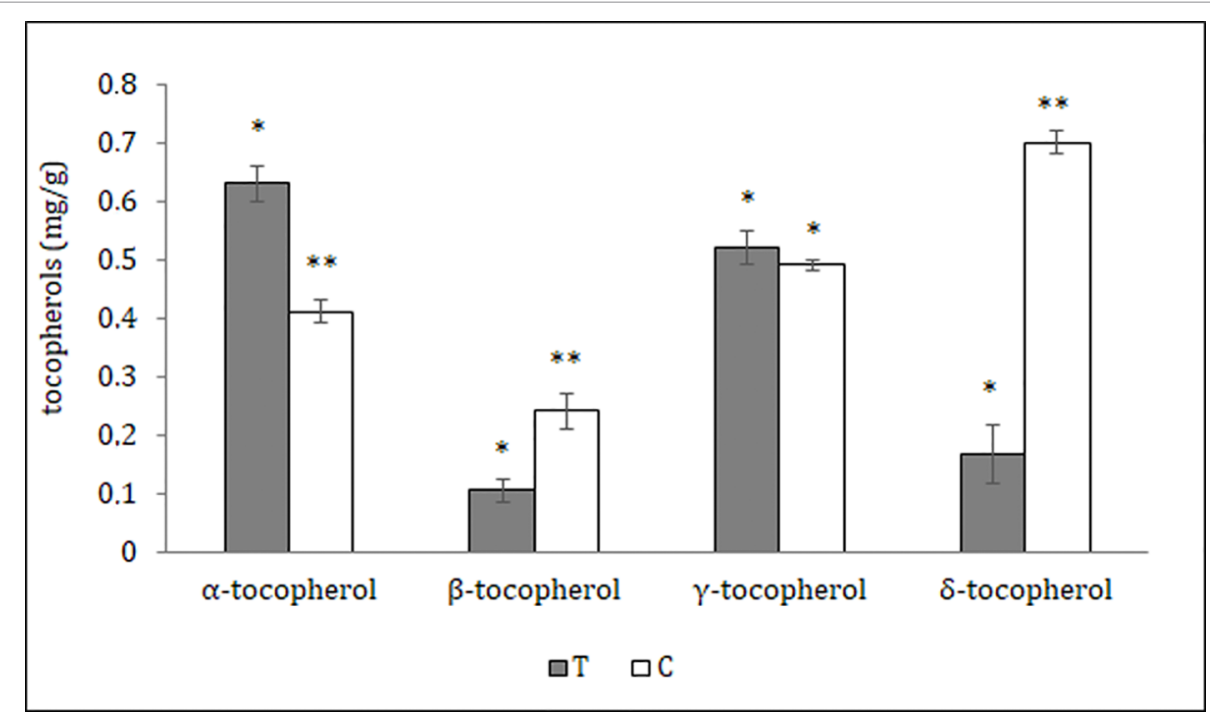

FIGURE 4 | Tocopherols content of different Theobroma cacao seed parts; T, tegument; C, cotyledons (see Materials and Methods). The results are expressed in milligram/gram sample \pm SD of three replicates. Different symbols indicate statistically significant differences according to least significant difference test $(p \leq 0.05)$.

TABLE 2 | Sterols content in different Theobroma cacao seed components.

\begin{tabular}{|c|c|c|c|c|c|}
\hline Sample & Campesterol & Campestanol & Stigmasterol & $\beta$-Sitosterol & $\Delta 5$-Avenasterol \\
\hline $\mathrm{T}$ & $11.2 \pm 1.2^{\mathrm{a}, \square}$ & $15.8 \pm 0.6^{a_{,}^{*}}$ & $18.6 \pm 2.6^{a, \dagger}$ & $62.3 \pm 3.5^{\mathrm{b}, \bullet}$ & $29.6 \pm 0.5^{b, \neq}$ \\
\hline C & $5.62 \pm 0.8^{b, \square}$ & $8.6 \pm 1.1^{c, *}$ & $16.2 \pm 0.6^{b, \dagger}$ & $52.3 \pm 5.1^{\mathrm{c}, \bullet}$ & $23.6 \pm 3.5^{c, ~} \neq$ \\
\hline EA & $1.36 \pm 0.3^{c, \square}$ & $12.1 \pm 1.8^{\mathrm{b}, \dagger}$ & $8.6 \pm 1.7^{\mathrm{c},{ }^{*}}$ & $72.3 \pm 6.42^{a, \bullet}$ & $42.3 \pm 1.4^{a, \neq}$ \\
\hline
\end{tabular}

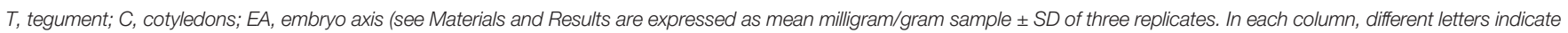
statistically significant differences according to least significant difference (LSD) test ( $p \leq 0.05)$; in each row, different symbols indicate statistically significant differences according to $L S D$ test $(p \leq 0.05)$. 
TABLE 3 | Fatty acids content in different Theobroma cacao seed components.

\begin{tabular}{|c|c|c|c|c|c|c|c|}
\hline Sample & $\begin{array}{c}\text { Palmitic acid } \\
\text { C16:0 }\end{array}$ & $\begin{array}{c}\text { Palmitoleic acid } \\
\text { C16:1 }\end{array}$ & $\begin{array}{c}\text { Stearic acid } \\
\text { C18:0 }\end{array}$ & Oleic acid C18:1 & $\begin{array}{c}\text { Linoleic acid } \\
\text { C18:2 }\end{array}$ & $\begin{array}{l}\text { Linolenic acid } \\
\text { C18:3 }\end{array}$ & $\begin{array}{c}\text { Arachidic acid } \\
\text { C20:0 }\end{array}$ \\
\hline $\mathrm{T}$ & $19.62 \pm 0.6^{b, \dagger}$ & $9.52 \pm 0.8^{b, \square}$ & $49.56 \pm 1.6^{b, \bullet}$ & $41.92 \pm 1.2^{b, f}$ & $1.27 \pm 0.2^{a}$ & $0.23 \pm 0.05^{a}$ & $13.03 \pm 0.2^{\mathrm{a},{ }^{*}}$ \\
\hline $\mathrm{C}$ & $22.21 \pm 1.2^{\mathrm{a}, \dagger}$ & $5.23 \pm 0.7^{c, \square}$ & $43.56 \pm 2.1^{c, \ddagger}$ & $46.95 \pm 2.7^{a, \bullet}$ & $0.36 \pm 0.02^{b}$ & $0.28 \pm 0.02^{a}$ & $11.23 \pm 0.4^{*} a$ \\
\hline EA & $24.68 \pm 0.9^{a, \dagger}$ & $13.55 \pm 1.8^{a, *}$ & $52.36 \pm 1.8 a^{\bullet}$ & $37.9 \pm 1.8^{\mathrm{c}, \mp}$ & $1.06 \pm 0.03^{a}$ & $0.38 \pm 0.08^{a}$ & $11.23 \pm 1.2^{\mathrm{a}, \square}$ \\
\hline
\end{tabular}

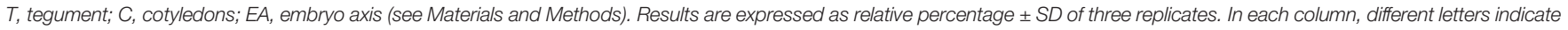

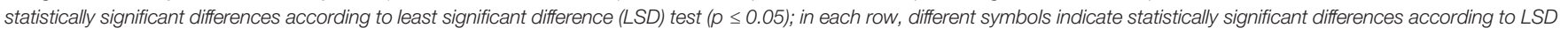
test $(p \leq 0.05)$.

portions [i.e., pulp or mucilage (endocarp), $\mathrm{T}$ and $\mathrm{C}$ ]. The highest polyphenols diversity was observed in the whole seed (with and without mucilage), and a characteristic polyphenol pattern was observed in different portion of the seed. Caffeic acid and p-cumaric acid are involved in lignin synthesis, so the higher amounts of these phenols detected in $\mathrm{T}$ respect to $\mathrm{C}$ can be probably related to a high presence of cells with lignified walls. In C phenolic compounds were located in big vacuolated polyphenolic cells; in some of these cells the presence of anthocyanins and epicatechin, was also highlighted vanillin staining confirmed the absence of epicatechin and catechin in the $\mathrm{T}$, indeed, as evident in phytochemical analysis, epicatechin is the predominant one in $\mathrm{C}$ and absent in the $\mathrm{T}$. Catechin and epicatechin are known to be the most abundant flavonoid compounds in cocoa powder; they play a role in plant immunity, growth regulation and support nutrient uptake and photosynthesis (Natsume et al., 2002; Jalil and Ismail, 2008; Prakash et al., 2019).

The presence of phenolic compounds in pulp was demonstrated by Endraiyani et al. (2016), which outlined the thermolability of these substances, but our cytological observations did not confirm that: the osmium and toluidine blue staining did not highlight phenols in the pulp tissue, probably because they are dissolved in the big vacuoles. Polyphenolic substances were, instead, observed in periphery cells of mesocarp, where they appeared reorganized in round vesicles, probably due to fixing in glutaraldehyde (Martini et al., 2008). They were also well evident in the embryo axis, where they localized in the external layers and near the vascular tissues. Even if also non-phenolic substances can be responsible for the antioxidant activity, phenolic content could be used as an indicator of antioxidant activity (TEAC), which was the highest in the T. In T, polyphenolic cells were evident in the testa but the histological localization of few polyphenolic cells in our samples did not seem to justify the high presence detected by chemical analysis. Moreover, TEAC was higher in SM than in S: this is probably connected to a higher presence of ferulic acid, caffeic acid, cumaric acid and syringic acid in the seed with mucilage. Other important components of cocoa beans are represented by fatty acids and phytosterols; the content of saturated and unsaturated fatty acids, bound in triglycerides, influence cocoa butter hardness and consequently its commercial value.
Among the analyzed fatty acids, the stearic and oleic acids were the most abundant in all the seed components ( $T, C$ and embryo axis). In particular the content of stearic acid is higher in embryos with respect the other seed parts whereas the amount of oleic acid is higher in C. Stearic acid is particularly appreciated, as it did not seem to increase the level of total cholesterol and low-density lipoprotein (LDL)-cholesterol in serum unlike the other saturated acid (Yu et al., 1995). In embryos the C16:0 and C18:0 were the predominant SFA, and this represent an advantage because the yield of ATP molecules during complete oxidation is higher than UFA.

Fatty acids, either free or as part of complex lipids, are important constituent of membranes or other cellular structures but also represent one of the storage substances of cocoa seed probably localized in lipid globules. In cocoa, as observed by Bayés-García et al. (2019), lipid droplets or lipid globules represent almost the $50 \%(\mathrm{w} / \mathrm{w})$ in fresh cacao beans and serve as important reservoirs of lipids, but also as substrates for multiple cellular processes; in our observations they occupied almost the entire volume of small isodiametric cells of cotyledon mesophyll.

The cocoa seeds were also rich in plant sterols, which had protective effects on the oxidation of lipids as result of synergistic interactions with tocopherols (Caporaso et al., 2018); they also regulate the fluidity and permeability of plant cell membranes, in a similar manner as cholesterol in mammalian. Moreover, these compounds have a beneficial effect on the human health as they seemed to contribute to reduce the level of LDL cholesterol in blood serum (Wollgast and Anklam, 2000; Andújar et al., 2012). In cocoa seeds, we observed a different distribution of the analyzed sterols: $\beta$ sitosterol and $\Delta 5$-avenasterol were the most abundant, above all in the embryo axis; stigmasterol and campesterol were less present in EA and more abundant in T; campestanol level was again higher in $\mathrm{T}$ but lower in $\mathrm{C}$. The specific localization of different kind of sterols was related probably with a peculiar function. Stigmasterol, for instance, is generally not involved in the regulation of membrane characteristics, but in cell proliferation and proton pumping (Hartmann, 1998). Tocopherol also showed a differential distribution in $\mathrm{T}$ and $\mathrm{C}$. Content, composition and presence of tocopherols varies widely in different plant tissues, moreover, both plant growth and development affect the levels of tocopherol content and 
composition, which changes for example during senescence, chloroplast to chromoplast conversion, fruit ripening and seed development (Arrom and Munné-Bosch, 2010; Falk and Munne-Bosh, 2010).

\section{CONCLUSIONS}

This study provides for the first time a whole picture of the distribution of many important compounds in cocoa, as until now only the localization of single chemicals in specific seed structures had been investigated (Dangou et al., 2002; Martini et al., 2008; Elwers et al., 2010). New information about cytohistological characteristics of cocoa seeds were also reported, as the storage role of big vacuolated cells present in $\mathrm{C}$ tissue. These cells can accumulate different compounds; anthocyanins

\section{REFERENCES}

Afoakwa, E. O. (2010). Chocolate science and technology (Oxford, UK: WileyBlackwell Publishers), 3-22.

Andersson, M., Koch, G., and Lieberei, R. (2006). Structure and function of the seed coat of Theobroma cacao L. and its possible impact on flavour precursor development during fermentation. J. Appl. Bot. Food Qual. 80, 458-462.

Andújar, I., Recio, M. C., Giner, R. M., and Ríos, J. L. (2012). Cocoa polyphenols and their potential benefits for human health. Oxid. Med. Cell. Longev. 23. doi: $10.1155 / 2012 / 906252$

Aprotosoaie, A. C., Mihai, C. T., Vochita, G., Rotinberg, P., Trifan, A., Luca, S. V., et al. (2016). Antigenotoxic and antioxidant activities of polyphenolic extract from Euroepan Dracocephalum moldavica L. Ind. Crops Prod. 79, 248-257. doi: $10.1016 /$ j.indcrop.2015.11.004

Arrom, L., and Munné-Bosch, S. (2010). Tocopherol composition in flower organs of Lilium and its variations during natural and artificial senescence. Plant Sci. 179, 289-295. doi: 10.1016/j.plantsci.2010.05.002

Batista, N. N., Andrade, D. P., Ramos, C. R., Dias, D. R., and Schwan, F. R. (2016). Antioxidant capacity of cocoa beans and chocolate assessed by FTIR. Food Res. Int. 90, 313-319. doi: 10.1016/j.foodres.2016.10.028

Bayes-Garcia, L., Aguilar-Jimenes, M., Calvet, T., Kovano, T., and Sato, K. (2019). Crystallization and melting behavior of cocoa butter in lipid bodies of fresh cacao beans. Cryst. Growth Des. 19 (7), 4127-4137. doi: 10.1021/ acs.cgd.9b00570

Beliz, H., and Grosch, W. (1999). Food Chemistry. 2nd ed. (Berlin: SpringerVerlag).

Bertazzo, A., Comai, S., Mangiarini, F., and Chen, S. (2013). "Composition of Cacao Beans," in Chocolate in Health and Nutrition. Nutrition and Health, vol. 7 . Eds. R. Watson, V. Preedy and S. Zibadi (Totowa, NJ: Humana Press).

Biehl, B., Paasern, U., and Passern, D. (1977). Subcellular structures in fermenting cocoa beans. Effect of aeration and temperature during seed and fragment incubation. J. Sci. Food Agric. 28, 41-52.

Biehl, B. (1973). Veränderungen der subzellulären Structur in Keimblättern von Kakaosamen (Theobroma cacao L.). Z.Lebesm. Unters. For. 153, 137-150.

Bruni, R., Medicia, A., Guerrinia, A., Scaliab, S., Polic, F., Romagnolid, C., et al. (2002). Tocopherol, fatty acids and sterol distributions in wild Ecuadorian Theobroma subincanum (Sterculiaceae) seeds. Food Chem. 77, 337-341. doi: 10.1016/S0308-8146(01)00357-0

Caporaso, N., Whitworth, M. B., Fowler, M. S., and Fisk, I. D. (2018). Hyperspectral imaging for non-destructive prediction of fermentation index, polyphenol content and antioxidant activity in single cocoa beans. Food Chem. 258, 343-351. doi: 10.1016/j.foodchem.2018.03.039

Carpenter, R. R., Hammerstone, J. F.Jr., Romanczyk, L. J. Jr., and Aitken, W. M. (1994). Lipid composition of Herrania and Theobroma seeds. J. Am. Oil Chem. Soc. 71, 845-851. doi: 10.1007/BF02540460 and epicatechins were for example detected only in some of them.

\section{DATA AVAILABILITY STATEMENT}

The datasets generated for this study are available on request to the corresponding author.

\section{AUTHOR CONTRIBUTIONS}

LR conceived the work. MC and LR performed microscopy analyses. CZ performed chemical analyses. MC performed statistical analyses. LR drafted the manuscript and MC and CZ critically revised the draft. All the authors approved the version of the manuscript to be published.
Cook, N. C., and Samman, S. (1996). Flavonoids-chemistry, metabolism, cardioprotective effects, and dietary sources. J. Nutr. Biochem. 7, 66-76. doi: 10.1016/S0955-2863(95)00168-9

Cooper, K. A., Donovan, J. L., Waterhouse, A. L., and Williamson, G. (2008). Cocoa and health: a decade of research. Bri. J. Nutr. 99, 1-11. doi: 10.1017/ S0007114507795296

Corporación Venezolana de Guayana (CVG). (2006). Informa Técnico. Principales Cultivos y Rubros Potenciales en Áreas Agrícolas del Estado Delta Amacuro. Convenio Corporación Venezolana de Petróleo-Corporación Venezolana de Guayana.

Dangou, J. S., Hocher, V., Ferrière, N., Fulcheri, C., Morard, P., and Alemanno, L. (2002). Histological and biochemical characterization of Theobroma caco L. endosperm during seed development. Seed Sci. Res. 12, 91-100. doi: 10.1079/ SSR2002101

Earp, C. F., McDonough, C., Awika, J. M., and Rooney, L. W. (2004). Testa development in the caryopsis of Sorghum bicolor (L.) Moench. J. Cereal S. 39 (2), 303-311. doi: 10.1016/j.jcs.2003.11.005

Elwers, S., Zambrano, A., Rohsius, C., and Lieberei, R. (2010). Histological features of phenolic compounds in fine and bulk cocoa seed (Theobroma cacao L.). J. Appl. Bot. Food Qual. 83, 182-188.

Endraiyani, V., Ludescher, R. D., Di, R., and Karve, M. V. (2016). Total phenolics and antioxidant capacity of cocoa pulp: processing and storage study. J. Food Process. Pres. doi: 10.1111/jfpp.13029

Engler, M. B., and Engler, M. M. (2004). The vasculoprotective effects of flavonoid-rich cocoa and chocolate. Nutr. Res. 695-706. doi: 10.1016/ j.nutres.2004.05.001

Falk, J., and Munne-Bosch, S. (2010). Tocochromanol functions in plants: antioxidation and beyond. J. Exp. Bot. 61, 1549-1566. doi: 10.1093/ jxb/erq030

Feder, N., and O’Brien, T. P. (1968). Plant microthecnique: some principles and new methods. Am. J. Bot. 55 (1), 123-142. doi: 10.2307/2440500

Gómez, M., and Azócar, A. (2002). Áreas potenciales para el desarrollo del cultivo del Cacao en el estado Mérida. Agronomía Trop. 52 (4), 403-425.

Hartmann, M. A. (1998). Plant sterols and the membrane environment. Trends Plant Sci. 3 (5), 170-175. doi: 10.1016/S1360-1385(98)01233-3

Hui, Y. H., Castell-Perez, E., Cunha, L. M., Guerrero-Legarreta, I., Liang, H. H., Lo, Y. M., et al. (2006). Handbook offood science, technology, and engineering Vol. 4 (Boca Raton: Taylor \& Francis).

Jalil, A. M., and Ismail, A. (2008). Polyphenols in cocoa and cocoa products: is there a link between antioxidant properties and health? Molecules 13, 2190-2219. doi: 10.3390/molecules 13092190

Martini, M. H., Figueira, A., Lenci, C. G., and De queiroz Tavares, D. (2008). Polyphenolic cells and their interrelation with cotyledon cells in seven species of Theobroma (Sterculiaceae). Rev. Brasil Bot. 31 (3), 425-431. doi: 10.1590/ S0100-84042008000300006 
Miliauskas, G., Venskutonis, P. R., and Beek, T. A. (2004). Screening of radical scavenging activity of some medicinal and aromatic plant extracts. Food Chem. 85, 231-237. doi: 10.1016/j.foodchem.2003.05.007

Ministerio del Poder Popular para la Ciencia y Tecnología (MPPCT). (2006). Informe Técnico sobre Actividades de la Red de Cacao del Municipio Tucupita del Estado Delta Amacuro. Programa Municipio Innovador. pp. 8

Natsume, M., Osakabe, N., Takizawa, T., Nakamura, T., Miyatake, H., Hatano, T., et al. (2002). "Analysis of polyphenol constituents in cocoa and chocolate", in Quality Management of Nutraceuticals. Eds. C.-T. Ho and Q. Y. ZengACS Symposium Series 803 (Washington, DC, USA: American Chemical Society), 180-198.

O'Brien, T. P., and Mccully, M. E. (1981). The study of plant structure principles and selected methods (Melbourne, Australia: Termarcarphi).

Ortega, N., Romero, M. P., Macià,A., Reguant, J., Anglès, N., et al. (2008). Obtention and characterization of phenolic extracts from different cocoa sources. J. Agric. Food Chem. 56, 9621-9627. doi: 10.1021/jf8014415

Othman, A., Jalil, A. M. M., Weng, K. K., Ismail, A., Ghani, N., and Adenan, I. (2010). Epicatechin content and antioxidant capacity of cocoa beans from four different countries. Afric. J. Biotech. 9 (7), 1052-1059. doi: 10.5897/AJB09.1219

Prakash, M., Basavaraj, B. V., and Chidambara Murthy, K. N. (2019). Biological functions of epicatechin: plant cell to human cell health. J. Funct. F. 52, 14-24. doi: 10.1016/j.jff.2018.10.021

R Core Team. (2017). R: A language and environment for statistical computing (Vienna, Austria: R Foundation for Statistical Computing). URL https://www.R-project.org/.

Reale, L., Rosati, A., Tedeschini, E., Ferri, V., Cerri, M., Ghitarrini, S., et al. (2017). Ovary Size in Wheat (Triticum aestivum L.) is Related to Cell Number. Crop Sci. (2017), 914-925. doi: 10.2135/cropsci2016.06.0511

Reyes, H., and Capriles de Reyes, L. (2000). El Cacao en Venezuela. Venezuela Moderna tecnología para su cultivo (C.A. Caracas, Venezuela: Editado por Chocolates El Rey).

Segall, S. D., Artz, W. E., Raslan, D. S., Ferraz, V. P., and Takahashi, J. A. (2005). Analysis of triacylglycerol isomers in Malaysian cocoa butter using HPLCmass spectrometry. Food Res. Int. 38, 167-174. doi: 10.1016/ j.foodres.2004.09.008

Sen, C. K., Khanna, S., and Roy, S. (2007). Tocotrienols in health and disease, The other half of the natural vitamin E family. Mol. Aspects Med. 28, 692-728. doi: 10.1016/j.mam.2007.03.001

Shukla, V. K. S. (2005). Bailey's Industrial Oil and Fat Products. Eds. F. Shahidi (Hoboken (USA): John Wiley \& Sons, Inc.), 159-173.

Simoneau, J. A., Veerkamp, J. H., Turcotte, L. P., and Kelley, D. E. (1999). Markers of capacity to utilize fatty acids in human skeletal muscle: relation to insulin resistance and obesity and effects of weight loss. FASEB J. 13 (14), 2051-2060. doi: 10.1096/fasebj.13.14.2051

Singleton, V. L., and Rossi, J. A. (1965). Colorimetry of total phenolics with phosphomolybdic-phosphotungstic acid reagents. Am. J. Enol. Vitic 16, 144-158.
Staphylakis, K., and Gegiou, D. (1985). Free, esterified and glucosidic sterols in cocoa. Lipids 11, 723-728. doi: 10.1007/BF02534394

Tokede, O. A., Gaziano, J. M., and Djoussè, L. (2011). Effects of cocoa products/ dark chocolate on serum lipids: a meta-analysis. Eur. J. Clin. Nutr. 65, 879-886. doi: 10.1038/ejcn.2011.64

Torres-Moreno, M., Torrescasana, E., Salas-Salvadó, J., and Blanch, C. (2015). Nutritional composition and fatty acids profile in cocoa beans and chocolates with different geographical origin and processing conditions. Food Chem. 166, 125-132.

Tzin, V., Galili, G., and Aharoni, A. (2012). "Shikimate Pathway and Aromatic Amino Acid Biosynthesis," in eLS (Chichester: John Wiley \& Sons, Ltd). doi: 10.1002/9780470015902.a0001315.pub2

Walker, R. P., Chen, Z. H., Johnson, K. E., Famiani, F., Tecsi, L., and Leegood, R. C. (2001). Using immunohistochemistry to study plant metabolism: the examples of its use in the localization of amino acids in plant tissues, and of phosphoenolpyruvate carboxykinase and its possible role in $\mathrm{pH}$ regulation. J. Exp. Bot. 52 (356), 565-576. doi: 10.1093/jexbot/52.356.565

Wang, L., Nägele, T., Doerfler, H., Fragner, L., Chaturvedi, P., Nukarinen, E., et al. (2016). System level analysis of cacao seed ripening reveals a sequential interplay of primary and secondary metabolism leading to polyphenol accumulation and preparation of stress resistance. Plant J. 87, 318-332. doi: 10.1111/tpj.13201

Wollgast, J., and Anklam, E. (2000). Polyphenols in chocolate: is there a contribution to human health? Food Res. Intern. 33, 449-459. doi: 10.1016/ S0963-9969(00)00069-7

Yu, S., Derr, J., Etherton, T. D., and Kris-Etherton, P. M. (1995). Plasma cholesterol-predictive equations demonstrate that stearic acid is neutral and monounsaturated fatty acids are hypocholesterolemic. Am. J. Clin. Nutr. 61, 1129-1139. doi: 10.1093/ajcn/61.4.1129

Zainal, B., Abdah, M. A., Taufiq-Yap, Y. H., Roslida, A. H., and Rosmin, K. (2014). Anticancer agents from non-edible parts of theobroma cacao. Nat. Prod. Chem. Res. 2, 134. doi: 10.4172/2329-6836.1000134

Conflict of Interest: The authors declare that the research was conducted in the absence of any commercial or financial relationships that could be construed as a potential conflict of interest

Copyright (C) 2019 Cerri, Reale and Zadra. This is an open-access article distributed under the terms of the Creative Commons Attribution License (CC BY). The use, distribution or reproduction in other forums is permitted, provided the original author(s) and the copyright owner(s) are credited and that the original publication in this journal is cited, in accordance with accepted academic practice. No use, distribution or reproduction is permitted which does not comply with these terms. 